\title{
Dynamics to the study of coping strategies of rural farm communities in the context of climate change and socioeconomic challenges: the Nigerian example
}

\author{
Ahmed A. O., Nosiru M. O., Tokede A. M. \\ Department of Forest Economics and Extension, Forestry Research Institute of Nigeria. \\ doi:
}

\begin{abstract}
The issue of climate change is predicted to have undesirable consequence on agricultural production and food security in sub-Saharan Africa. This impact, however, is expected to vary spatially across and within countries in the region (and across socio-economic groups). Areas with high climatesensitive agricultural production systems due to their over reliance on rainfed subsistence agriculture have been identified as the most vulnerable to climate change. Most of these countries already battle with the issues of poverty, food insecurity, health, and other basic social needs. The compound effect of climate change is therefore deleterious to the growth of the economies in such countries placing them at the high end of the climate change vulnerability spectrum. The aim of this paper is to examine the climate change, socioeconomic vulnerabilities and coping strategies employed by farming communities in Nigerian rural farm families to alleviate the negative impact of potential challenges.
\end{abstract}

KEYWORDS

Climate Change,

Socioeconomic,

Strategies,

Challenges,

Nigeria.

\section{CORRESPONDING}

\section{AUTHOR}

Ahmed, A. O.

ahmadsquare8@gmail.com

\section{INTRODUCTION}

The nexus between the environment and socioeconomic issues of rural farm communities became more visible in 1980s and thereby difficult to jettison. Subsequently, the issue of climate change emerged in response to this growing realization of the need to balance economic and social progress with concern for the environments well as the stewardship of natural resources. This led to the United Nations Framework Convention on Climate Change (UNFCCC) in 2007, in which climate change is defined as "a change of climate which is attributed directly or indirectly to human activity that alters the composition of the global atmosphere and which is in addition to natural climate variability observed over comparable time periods". Temperature has risen significantly since the 1980s (Enete IC, 2014, 234; Federal Ministry of Environment, 2014).

Climate projections for the coming decades reveal a significant increase in temperature over all the ecological zones (Akande et al. 2017). The issue of climate change has been a central focus in many global discussions concerning poverty, food insecurity, environmental sustainability, human health, global economy, and many other sociopolitical discourses. This paper explores climate change vulnerabilities and coping strategies employed by farming communities in Nigeria rural farm families to alleviate the negative impact of potential extreme events as drought, flood and bushfires.

World population growth has continued, and although the demand for food production has more than doubled since the pre-industrial era, 
productivity is declining due to climate change and climate variability. Empirical evidence supports climate change-induced decline in crop and livestock productivity globally (IPCC 2007; Deressa et al. 2008; IISD 2007; Lobell et al. 2008), more especially in weather-sensitive agricultural production regions such as sub-Saharan Africa.

At the moment in Nigeria, the trends are that the climate change and socioeconomics challenges of the rural farm families are growing. In rural areas, climate change and socioeconomic challenges are associated with different circumstances like drought, seasonal changes in food prices and lack of adequate land. These challenges also fluctuate more in the rural areas and as well cause seasonal migration to the urban areas. Be that as it may, the socioeconomic situation of the family depends on their family cycle as well.

Many families, with small children and elderly people to take care of, are poorer than others. Accidents might also change the whole socioeconomic of the family because social security is not often provided in the rural areas. In the developing countries, accidents occur more often due to bad roads, vehicles, misused laws and orders (Habitat 1996). A good understanding of the aftermath effect of climate change on the livelihood of rural farm families, possible coping measures employed, and factors influencing the choice of a specific coping strategy to climate change will enhance policies towards tackling the challenges that climate change poses to farming communities.

\section{Dimension of Conceptual Issues}

\section{Climate Change}

Climate change is a global phenomenon with varying degrees of severity by regions with SubSaharan Africa being the worst hit. Indeed, this is confirmed by several studies (see for example,
Deressa 2006; Moussa et al. 2006; Jain 2006; Hassan et al. 2008; Molua et al. 2006; Mano et al. 2006). Climate change will further reduce access to drinking water, negatively affect the health of poor people, and will pose a real threat to food security in many countries in Africa, Asia and Latin America. According to IPCC (2001), climate change refers to any change in climate over time, whether due to natural variability or as a result of human activity. It can also be seen as change in climate which is attributed directly or indirectly to human activities that alter the composition of the global atmosphere and which are in addition to natural variability observed over comparable time periods (IPCC 2007). Climate change has in recent times manifesting in variations of different climate parameters including cloud cover, precipitation, temperature ranges, sea levels and vapor pressure (Ministry of Environment of the Federal Republic of Nigeria, MOEFRN 2003).

\section{Rural Farm Families and Climate Change Challenges in the Nigerian context}

The key climate changes issues facing Nigerian rural farm families can be captured broadly in terms of flood, bush burning and drought. Generally, floods result intensively from heavy and high intensity rainfall, coupled with hand glove watershed management. Other human activities such as blockage of river/drainage channels, poor dam construction, unplanned rapid urbanization, deforestation as well as clearing land for agricultural purposes are contributing factors to flooding. There is also a direct link between erosion and flooding, thus with loss of farmlands, land resources depletion and reduction in agricultural productivities and outputs.

Loss of land resources for other developmental purposes resulting from flooding also lead to destruction of properties, social amenities and loss of lives. The outcomes of these are a reduction in the productivity of people in the short and long 
terms, sacrifice in output and incomes, and increasing difficulty for rural farm families (Omotesho et al. 2006).

The Northeast and the Northwest are the most vulnerable regions to drought and aridity, affecting the entire Savanna landscape of the Northern Nigeria, and resulting in a decline of socioeconomic activities around Lake Chad. The combination of rising heat and less rain has hastened desert encroachment, with loss of the wetlands, and fast reduction in the amount of surface water, flora and fauna resources on land (Abdulkadir et al. 2017; Akande et al. 2017; Federal Ministry of Environment 2014). Drought conditions in parts of northern Nigeria have resulted in less drinking water. Government data demonstrates that rural households harvest rain for more than half their total water consumption and northern groundwater tables have dropped sharply over the last half century, owing in part to less rain (Sayne 2011). However, the Southwest and Southeast are relatively less vulnerable than other parts of the country.

The concept of drought has divergent meaning across disciplines, regions or zones and the severity of impact. Regardless, some authors have attempted to give a general perspective on what drought is. According to Wilhite et al. (2000), drought is described as a natural hazard that differs from other hazards because it has a slow onset, progresses over months or even years, and affects a large spatial region and causes little cultural damage. The persistent or lingering nature of drought is again echoed in its definition found in the Encyclopedia Britannica. As the lack or insufficiency of rain for an extended period that causes a considerable hydrologic imbalance and, consequently, water shortages, crop damage, stream flow reduction and depletion of groundwater and soil moisture (Dietz et al. 2001).

Drought is an extreme rainfall deficit and the resulting periods of low flow of water, which can have severe effects on water managements in terms of river pollution, reservoir design and management, irrigation and drinking water supply (Hisdal \& Tallaksen 2000). The definition of drought differs due to several reasons: it affects all climatic regions at varying degrees, it affects diverse economic and social factors, and the demands people place on water differs markedly across regions (Wilhite 1996; Dietz et al. 2001; Moneo \& Iglesias 2004).

The incidence of flooding is a common occurrence in Southern ecological zone of Nigeria. The southern ecological zone is largely known for high rainfall and an irregular rainfall pattern, with Guinea savannah experiencing gradually increasing temperatures (Ebele \& Emodi 2016). Large proportions of the population in the Southwest rainforest zone and Southeast region live in rural areas and engage in agricultural activities for their livelihood (Nnadi et al. 2019; Avanladeet et al. 2018). Within Southern Nigeria, the South-south (Niger Delta region) is the most vulnerable, due to sea level rise, increased precipitation, coastal erosion and flooding - which has resulted in the displacement of many settlements (Matemilola 2019; Federal Ministry of Environment 2014; Sayne 2011).

Bushfires occur during the dry seasons when farmers are preparing their land for the next growing period. Their incidence is easily avoidable than any of the extreme events. While some households cope by either improving their farm maintenance practices or educating members of the household and community about the dangers of bushfires, others did nothing. The farm maintenance practices adopted include clearing of weeds and creating fire belts around farm and house. This prevents the spread of fire when preparing the farmland for the next growing season. 


\section{Rural Farm Families and Socioeconomic Challenges in the Ecosystem Dimension}

Socioeconomic challenge of the rural farm families in the context of ecosystem is another dimension to examine because natural and humanmade threats, socio-cultural problems as well as direct and indirect consequences of socioeconomic development have contributed to the erosion of biodiversity at all levels. According to Olayemi $\boldsymbol{e t}$ al. (2017), almost $30 \%$ of the forest cover has been lost through human activity. In essence, about 96 percent of the original 20 percent forest area has been cleared. This has not only resulted in massive loss of rich and diverse forest floral and faunal of the rural farm families, but it also endangered their indigenous species.

In the same way, most parts of the Savanna are being ravaged by man-induced desertification, causing ecosystem disturbance as well as biodiversity loss. In addition, extreme weather events, such as floods, can undermine economic growth through production and infrastructure losses and the need for extraordinary spending (Federal Government of Nigeria 2013). Several studies have revealed so many patterns of vulnerability stem primarily from the dominance of climatesensitive agricultural activities, poor infrastructural development and other socio-economic conditions in rural areas of the country (Madu 2016).

The Northern regions of Nigeria, for instance, which have higher degrees of rural dwellers, are more vulnerable to climate change (Madu 2016). In addition, extreme weather events, such as floods, can undermine economic growth through production and infrastructure losses and the need for extraordinary spending (Federal Government of Nigeria 2013). Given the importance of the agricultural sector to livelihoods and the economy in Nigeria, problems with crop yields and productivity can have an adverse effect on gross domestic product (Anabaraonye et al. 2019;
Solomon \& Edet 2018; Ogbuabor \& Egwuchukwu 2017; Ebele \& Emodi 2016). Farmers must contend with variations in climate and the risk of flooding (Nnadi et al. 2019; Avanlade et al. 2018).

\section{Coping Strategies Employed by Rural Farm Communities against Climate Change and Socioeconomic Challenges in Nigeria}

Several factors have been put forward to explain the presence or absence of coping strategies employed by rural farm families to climate change. Coping strategies focused on actions that would help to lessen the sensitivity of systems in different ecological zones in Nigeria (Federal Ministry of Environment 2014). Planned strategies include government intervention and public policy, such as investment in infrastructure, subsidies, research, innovation, and tax regimes (Jellason et al. 2019).

Autonomous adaptation involves coping strategies by farmers and others affected in rural settings. These include diversification, irrigation, change in planting date, crop and livestock insurance and using tolerant varieties of crops (Jellason et al. 2019). Below et al. (2012) acknowledge the role of public investment in rural infrastructure, a good education system that allows females equal education opportunities, availability of microcredit services, availability and technically efficient use of agricultural inputs, and availability of agricultural extension in improving adaptation in Mlali and Gairo villages in Tanzania.

Ishaya and Abaje (2008) find that lack of awareness and knowledge about climate change and adaptation strategies, lack of capital and improved seeds, and lack of water for irrigation played an important role in hindering coping strategies in Jema'a, Nigeria. While analyzing farmers' perceptions of climate change, governance, and adaptation constraints in the Niger Delta region of Nigeria, Nzeadibe et al. (2011) also point out that the factors responsible for hindering 
adaptation are inadequate information, limited awareness and knowledge about adaptation methods, and poor government attention to the phenomenon of climate change.

Adesoji and Ayinde (2013), downscaling the methods used by arable crop farmers to mitigate the negative impact of climate change in Osun State, Nigeria, suggest that age, household size, income, source of information and farm size are the main determinants of the choice of coping strategies implemented by farmers. In that study, the authors mention that the coping strategies which are regularly employed are use of different planting dates, multiple cropping, and cover cropping. In the same vein, studies find that the socio-economic characteristics of farmers determine their level of use of climate change coping strategies. Education level, degree of farming experience, use of extension services, access to weather information, access to agricultural inputs, level of household income and availability of credit are positively and significantly related to uptake of coping to climate change (Solomon \& Edet 2018; Oluwole et al. 2016). Avanlade et al. (2018) also observed in a study conducted in Osun state in Southwest Nigeria finds that length of farming experiences determines the level of awareness that farmers have about climate change, which in turn increase the likelihood of adopting climate change adaptation measures (Avanlade et al. 2018). At this juncture it is expedient to put forward some of the more notable coping strategies employed by rural farm communities in rural settings against climate change and socioeconomic challenges in Nigeria.

\section{Adaptation Strategies}

In Nigeria, various strategies have been made by the rural farm communities to reduce the effects of climate change and socioeconomic challenges in the country. According to Jellason et al. (2019), climate change and socioeconomic coping strategies implemented in the Northwestern
Nigerian varies across the region in the uptake of improved crop varieties and crop rotation. However, studies find that good practices, such as mulching and soil sealing, were adopted.

The adaptation strategies devised in Imo state in Southeast Nigeria can be linked to the studies of Okoroh et al. (2016) who categorized the adaptation strategies as follows: crop rotation mixed cropping practices and the use of water channels as draining systems, mulching, regular weeding, and conservation of soil moisture through appropriate tillage operation. In most cases, all of which have been undertaken by more than half of the farmers studied. It was also observed by (Ifeanyi-obi \& Nnadi 2014) that adaptation strategies, such as improvement in farm input and movement toward more disease resistant crop varieties, are further adopted.

Studies by Enete $\boldsymbol{e t}$ al. (2015) summarized that crop cover is proving to be effective in conserving soil and protecting against climatic factors, such as excessive heat/dry spell, heavy and erratic rainfall, and erosion. Oluwole et al. (2016) stress further that the rural farmers in Oyo and Ekiti States in Southwest Nigeria devise the following adaptation strategies against climate change which include: cover crop plantation, application of fertilizer, cultivation of improved varieties, adopting mixed cropping. The variation in the form of strategies adopted among the farmer systems from the differences in access to capital, information on the use of different climate change adaptation strategies and type of arable crop grown by the individual farmers. Nzeadibe et al. (2011) studied strategies implemented in the Niger Delta by farmers. They include planting with early rainfall; adopting mixed farming; using proper preservation of seeds as an adaptive strategy; and crop cover.

\section{Technology Adoption}

Other noticeable coping strategy employed by rural farm families in rural settings against climate 
change and socioeconomic challenges in Nigeria is adoption of technology. The technology adopted by many rural farm families in various ecological regions in Nigeria includes crop diversification and the adoption of climate-adapted crops. The drought-tolerant and early maturing varieties of crops that would allow for profitable crop harvest with less rain and prolonged dry periods as well as requiring medium level financial commitment are planted (Achike et al. 2019; Enete IC 2014; Federal Ministry of Environment 2014). Amadi et al. (2015) further noted that improved soil management practices and crop cover, such as the use of potatoes, melon, and groundnut, are also used by farm families to protect topsoil from the effects of soil erosion as well as flooding.

\section{Extension Services}

Without mincing words, extension services are essential to improving agricultural productivity by providing farmers with useful farming and weatherrelated information and skills training that can enhance their productivity (Oluwole et al. 2016; Federal Ministry of Environment 2014). Be that as it may, there is no doubt that the useful farming and weather-related information and skills training that the extension professionals provided the farmers in the rural communities the short run as well as in the long run help them in mitigating the impacts of flooding in the farms for in instance in the Southeast Nigeria (Nnadi et al. 2019) an by extension more effectively counter the impacts of climate change (Ifeanyi-obi \& Nnadi 2014).

\section{CONCLUSION}

The preoccupation of this paper is to establish the coping strategies the rural farm communities devised against the effect of climate change and socioeconomic challenges that are bedeviling their farming communities. In doing so, an attempt has been made to show that a good understanding of the aftermath effect of climate change and as well socioeconomic challenges on the livelihood of farming households, possible coping measures employed, and factors influencing the choice of a specific coping strategy to climate change will enhance policies towards tackling the challenges that climate change poses to farming communities.

It is the opinion of the author that, given the presence of Nigerian Meteorological Agency (NIMET) that produces weather information, the rural farmers should be provided with and have easy access to better climate change information and rural areas should be provided with adequate social and economic infrastructure facilities that will be beneficial to the rural farm communities.

\section{REFERENCE}

Abdulkadir A. et al. (2017). Climate change and its implications on human existence in Nigeria: a review. Bayero Journal of Pure and Applied Sciences, 10(2): 152-158.

Achike A. I. et al. (2019). Greenhouse gas emission determinants in Nigeria: Implications for trade, climate change mitigation and adaptation policies.

Akande, A. et al. (2017). Geospatial Analysis of Extreme Weather Events in Nigeria (19852015) Using Self-Organizing Maps. Advances in Meteorology.

Amadi S.O. and Udo S.O. (2015). Climate change in contemporary Nigeria: An empirical analysis of trends, impacts, challenges and coping strategies. IOSR Journal of Applied Physics, 7(2): 1-9.

Anley Y., Bogale A., and Haile-Gabriel A. 2007. Adoption decision and use intensity of soil and water conservation measures by smallholder subsistence farmers in Dedo district, Western Ethiopia. Land Degradation and Development 18: 289-302.

Ayanlade A. et al. (2017). Comparing smallholder farmers' perception of climate change with meteorological data: A case study from 
southwestern Nigeria. Weather and Climate Extremes 15: 24-33.

Building Nigeria's Response to Climate Change (BNRCC). (2011). National adaptation strategy and plan of action on climate change for Nigeria (NASPA-CCN). Prepared for the Federal Ministry of Environment Special Climate Change Unit.

Ebele N. E. and Emodi N. V. (2016). Climate change and its impact in Nigerian economy. Journal of Scientific Research \& Reports, 10(6): 1-13.

Elisha, I. et al. (2017). Evidence of climate change and adaptation strategies among grain farmers in Sokoto State, Nigeria. IOSR Journal of Environmental Science, Toxicology and Food Technology (IOSR-JESTFT), 11(3): 1-7.

Enete IC (2014). Impacts of climate change on agricultural production in Enugu State, Nigeria. Journal of Earth Science \& Climatic Change, 5(9): 234.

Federal Ministry of Environment (2014). United Nations Climate Change Nigeria. National Communication (NC). NC 2. 2014.

Few R. 2003. Flooding, vulnerability, and coping strategies: local responses to a global threat. Progress Development Studies 3(1): 43-58

Ifeanyi-obi C.C. and Nnadi F.N. (2014). Climate change adaptation measures used by farmers in South Nigeria. Journal of Environmental Science, Toxicology and Food Technology, 8(4).
Hassan R. and Nhemachena C. 2008. Determinants of African farmers' strategies for adapting to climate change: Multinomial choice analysis. African Journal of Agricultural and Resource Economics 2 (March): 1.

Jellason N. P. et al. (2019). Climate change perceptions and attitudes to smallholder adaptation in Northwestern Nigerian Drylands. Social Science, 8(31).

Madu I. A. (2016). Rurality and climate change vulnerability in Nigeria: Assessment towards evidence based even rural development policy. Paper presented at the 2016 Berlin Conference on Global Environmental Change, 23-24 May 2016 at Freie Universität Berlin.

Nnadi O. I. et al. (2019). Impacts of variability and change in rainfall on gender of farmers in Anambra, Southeast Nigeria. Heliyon 5. https://doi.org/10.1016/j.heliyon.2019.e02085

Okoroh J. P. et al. (2016) Climate Change Mitigation and Adaptation Strategies Used by Farmers in Imo State, Nigeria. Journal of Agricultural Extension, 20(2): 130-142.

Oluwole J. et al. (2016). Assessment of level of use of climate change adaptation strategies among arable crop farmers in Oyo and Ekiti States, Nigeria. Journal of Earth Science \& Climatic Change, 7: 369.

Solomon E. and Edet O. G. (2018) Determinants of climate change adaptation strategies among farm households in Delta State, Nigeria. Current Investigations in Agriculture and Current Research, 5(3). 